\title{
Surface Modified Polymer Microspheres Obtained by the Emulsion Copolymerization of 2-Methacryloyloxyethyl Phosphorylcholine with Various Vinyl Monomers
}

\author{
Kazuo SugIYama* and Hitoshi AoKI \\ Department of Industrial Chemistry, Faculty of Engineering, \\ Kinki University, Takaya, Higashihiroshima, 729-17 Japan
}

(Received September 6, 1993)

\begin{abstract}
A series of copolymer microspheres of 2-methacryloyloxyethyl phosphorylcholine (MPC) with comonomers (M) such as methyl-(MMA), ethyl-(EMA), n-butyl-(BMA), hexyl methacrylate (HMA), and styrene (St), poly(MPC-co-M), was prepared from the emulsifier-free emulsion copolymerization. From the kinetics of copolymerization of MPC and MMA, it was found that the initial rate of polymerization of MMA increased drastically in the presence of small amounts of MPC. A decrease in the yield of poly(MPC-co-MMA) microspheres and increase in that of its aggregates were observed with increasing content of the MPC moiety from 0 to $10 \mathrm{~mol} \%$ in feed. The diameters of poly(MPC-co-M) microspheres were much smaller than those of corresponding poly(M) microspheres except for poly(MMA) microspheres. It was confirmed from XPS measurements that the MPC moiety is localized on the surface of particles. A series of poly(MPC-co-M) microspheres was found to absorb bovine serum albumin (BSA) less than the corresponding poly(M) microspheres as the control. It was concluded that the reduction of adsorbtion of BSA on poly(MPC-co-M) is dependent on the hydrophilicity of comonomer M and the MPC composition on the surface of particles.

KEY WORDS Emulsion Copolymerization / 2-Methacryloyloxyethyl Phosphorylcholine / Vinyl Monomers / Surface Modified Polymer Microspheres / XPS / Albumin Adsorption /
\end{abstract}

Considerable attention has been paid to surface modified polymers by phosphorylcholine moieties, which exist on the extracellular surface of the lipid bilayer, in respect to biocompatibility and other properties. $^{1-3}$ Nakabayashi's group reported that potential blood biocompatible copolymers, comprising 2-methacryloyloxyethyl phosphorylcholine (MPC) and $n$-butyl methacrylate (BMA) moieties, reduce protein adsorption from human plasma ${ }^{4}$ and the activation of platelets. ${ }^{5,6}$ There is thus no doubt that the introduction of the zwitterionic head group of phosphatidylcholine into polymer is useful for improving thrombo-resistance. ${ }^{4-9}$

\footnotetext{
* To whom correspondence should be addressed.
}

On the other hand, well-controlled emulsion polymerization of vinyl monomers gives polymer microspheres with highly uniform size, extremely large surface area, and controlled surface charge density. Hence, the particles may be used as medical diagnostics, ${ }^{10}$ protein separators, ${ }^{11}$ and enzyme-immobilized materials. ${ }^{12}$ The particles are also employed to evaluate interactions between plasma proteins and polymer surfaces, using the polymer microsphere-column method ${ }^{5}$ other than polymer-coated glass beads. ${ }^{13}$ The polymer microspheres whose surfaces are modified with an analogous structure to biomembrane are also anticipated to be important polymer materials 
for various biomedical uses. Yamaguchi et al. reported surface modified polystyrene microspheres using the emulsion polymerization of styrene (St) in the presence of polymerizable and non-polymerizable phospholipids. ${ }^{14}$ In a previous paper ${ }^{15}$ we also reported the interactions between BSA and the copolymer microspheres obtained from the emulsion copolymerization of methyl methacrylate (MMA) and 2-[2-(methacryloyloxy)ethyldimethylammonio]-6-[4-(4-methoxyphenylazo)phenoxy]hexyloxyphosphate. In the course of our study as far as the functionalized polymer microspheres were concerned, our interest was directed to the immobilization of phosphorylcholine moiety on the surface of polymer microspheres. The present paper describes the kinetics for the emulsifier-free emulsion copolymerization of MPC with various vinyl monomers (M) and characterization of copolymer microspheres [poly(MPC-co-M)] as well as the interactions between BSA and poly(MPC-co-M) microspheres.

\section{EXPERIMENTAL}

\section{Reagents}

2-Hydroxyethyl-(HEMA), ethyl-(EMA), hexyl methacrylate (HMA), MMA, BMA, and St were purified by standard methods and distilled under reduced pressure of nitrogen.

Potassium persulfate (KPS) was recrystallized from water. Cation-(PK-212) and anionexchange resin (PA-312) used for purifying polymer microspheres were obtained from Mitsubishi Chemical Industries and cleaned according to the procedure described in the literature. ${ }^{16}$ Crystallized and lyophilized BSA was purchased from Sigma Chemical Co. and was used as obtained. Distilled and deionized water was used throughout the experiments.

\section{Preparation of $M P C$}

2-Chloro-1,3,2-dioxaphospholane (CDP), bp $42-43^{\circ} \mathrm{C} / 13 \mathrm{mmHg}$, was prepared by the method of Lucas et al. ${ }^{17}$ 2-Chloro-2-oxo-1,3,2-

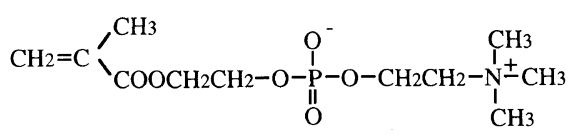

Figure 1. Structure of MPC.

$\lambda^{5}$-dioxaphospholane (COP), bp $91-92^{\circ} \mathrm{C} / 2$ $\mathrm{mmHg}$, was prepared in $65 \%$ yield by oxidation of CDP with oxygen following the method of Edmundson. ${ }^{18}$ MPC (Figure 1) was prepared by modifying the method described in literatures ${ }^{7,19}$ as follows: Into a $300 \mathrm{ml}$ three-necked round bottomed flask equipped with a magnetic stirrer, drying tube, $\mathrm{N}_{2}$ inlet tube, and dropping funnel, were placed $19.5 \mathrm{~g}$ $(0.15 \mathrm{~mol})$ of HEMA in $100 \mathrm{ml}$ of dry tetrahydrofuran (THF). After cooling with dry-ice/methanol at $-5^{\circ} \mathrm{C}, 20.8 \mathrm{~g}(0.15 \mathrm{~mol})$ of COP were added dropwise to the stirred solution under a stream of nitrogen for $1 \mathrm{~h}$. In our method, the reaction of HEMA with COP was performed in the absence of any acceptor for $\mathrm{HCl}$ evolved in the course of reaction in THF. The reaction was continued below $5^{\circ} \mathrm{C}$ while introducing nitrogen until evolution of $\mathrm{HCl}$ gas ceased. After reaction for $48 \mathrm{~h}$, the solution was evaporated under reduced pressure to give a colorless viscous oil, 2(2-oxo-1,3,2-dioxaphospholoyloxy)ethyl methacryate, followed by dissolving in $50 \mathrm{ml}$ of dry THF. After the solution was transferred to a $200 \mathrm{ml}$ glass pressure bottle at $-5^{\circ} \mathrm{C}$, $16.9 \mathrm{~g}(0.30 \mathrm{~mol})$ of trimethylamine in $50 \mathrm{ml}$ of dry THF were rapidly added at once. The closed glass bottle was shaken in a thermostat maintained at $40^{\circ} \mathrm{C}$ for $24 \mathrm{~h}$ and then allowed to stand in a refrigerator for $10 \mathrm{~h}$. The precipitate formed was filtered off and washed with dry THF to give white crystalline MPC in $29.8 \mathrm{~g}(67.3 \%)$ yield. mp. 137$140^{\circ} \mathrm{C} .{ }^{1} \mathrm{H}$ NMR spectra data of MPC obtained here were the same as those of MPC described in the literature. ${ }^{7}$ Anal. $\mathrm{C}: \mathrm{H}: \mathrm{N}=$ $43.91: 7.94: 4.44 \%$. Calcd for $\mathrm{C}_{11} \mathrm{H}_{22} \mathrm{NO}_{6} \mathrm{P}$ $(\mathrm{M}=295.273), \mathrm{C}: \mathrm{H}: \mathrm{N}=44.75: 7.72: 4.74 \%$. 


\section{Emulsion Polymerization}

Emulsifier-free emulsion polymerization was carried out according to the method in a previous paper. ${ }^{15}$ In brief, known amounts of MPC and comonomer were copolymerized by KPS as an initiator in water at $70^{\circ} \mathrm{C}$ under nitrogen stream for a given time, stirring mechanically with $350 \mathrm{rpm}$ speed of agitation. Polymer microspheres were purified as follows: The coarse particles and aggregates as nondispersed mass products were filtered through a glass filter (17G2), dried, and weighed. The filtrate was centrifuged at $12500 \mathrm{rpm}$ using a Sigma Laborzentrifugen 2-15, decanted and redispersed in water. After repeating this procedure three times, polymer microspheres were purified by treatment with the mixture of cation- and anion exchange resins.

\section{Measurements of Particle Size}

Particle size of polymer microspheres was determined by TEM at $180 \mathrm{kV}\left(5 \times 10^{-7}\right.$ Torr $)$ with a Topcon EM002B: A very dilute dispersion of polymer microspheres was dropped on a carbon-mounted copper sheet mesh (VECOGRID 400 mesh) and air-dried. Particle size was estimated by comparing TEM with polystyrene latex standard (Dow-Diagnostics, Uniform Latex Particle, $\phi 600 \mathrm{~nm}$, Lot No. 2F8E). Size distribution of particles was measured with a Pacific Scientific NICOMP 370 .

\section{$X$-Ray Photoelectron Spectroscopy (XPS)}

The surface of particles was analyzed by XPS using a Shimadzu ESCA 750: The emulsion of polymer microspheres was dropped on a stainless-steel holder and dried for a few hours. Measurements were made using $\mathrm{Mg}-K_{\alpha}$ in a vacuum of less than $5 \times 10^{-7}$ Torr. The ratio of the number of atoms for nitrogen and phosphorus to carbon was obtained based on relative sensitivity factors, 1.77 and 1.25 for $\mathrm{N}_{1 \mathrm{~s}} / \mathrm{C}_{1 \mathrm{~s}}$ and $\mathrm{P}_{2 \mathrm{p}} / \mathrm{C}_{1 \mathrm{~s}}$, respectively. The spectra of $N_{1 s}$ and $P_{2 p}$ were measured for 25 and 16 scans, respectively.

\section{Measurements of Equilibrium Water Content}

A polymer membrane was prepared from casting a $25 \mathrm{ml}$ of THF solution containing $200 \mathrm{mg}$ of dry polymer microspheres on mercury bath with $9.27 \mathrm{~cm}$ of diameter at room temperature. The membrane was dried in vacuo at $40^{\circ} \mathrm{C}$ for $10 \mathrm{~h}$, followed by immersing in $\mathrm{pH}$ 7.40 of phosphates buffer solution at $25^{\circ} \mathrm{C}$. After being in equilibrium for $24 \mathrm{~h}$, the membrane was taken off and excess solution was removed by light tamping between filter papers. The measurement was repeated three times for each sample. Equilibrium water content was calculated by the following equation ${ }^{7}$ :

$$
\begin{aligned}
& \text { Equilibrium water content }= \\
& \frac{\text { weight of water in the membrane }}{\text { weight of membrane swollen }}
\end{aligned}
$$

\section{Adsorption Procedure}

Interaction between BSA and polymer microspheres was measured at 0.01 of ionic strength adjusted with $\mathrm{NaCl}$ at $\mathrm{pH}$ 5.6: The specific surface area of polymer microspheres was calculated from the diameter determined by transmission electron microscopy (TEM) and the emulsion containing a definite concentration of the polymer microspheres was prepared for the adsorption experiment. A mixture of a known concentration of BSA aqueous solution and $40 \mathrm{~m}^{2} \mathrm{l}^{-1}$ of polymer microspheres was equilibrated at $25^{\circ} \mathrm{C}$ for $2 \mathrm{~h}$, followed by centrifugation at $12500 \mathrm{rpm}$ for $15 \mathrm{~min}$. The amount of BSA adsorbed on polymer microspheres was determined by the Lowry method. ${ }^{20}$ The amount of BSA adsorbed was calculated from the content of free BSA in water, measuring the absorbance at $750 \mathrm{~nm}$ of BSA by UV measurements with a Shimadzu UV-160A spectrophotometer.

\section{RESULTS AND DISCUSSION}

\section{Copolymerization of MPC with Various Vinyl Monomers}

Prior to the preparation of copolymer 
Table I. Condition for the emulsion copolymerization of MPC and various vinyl monomers

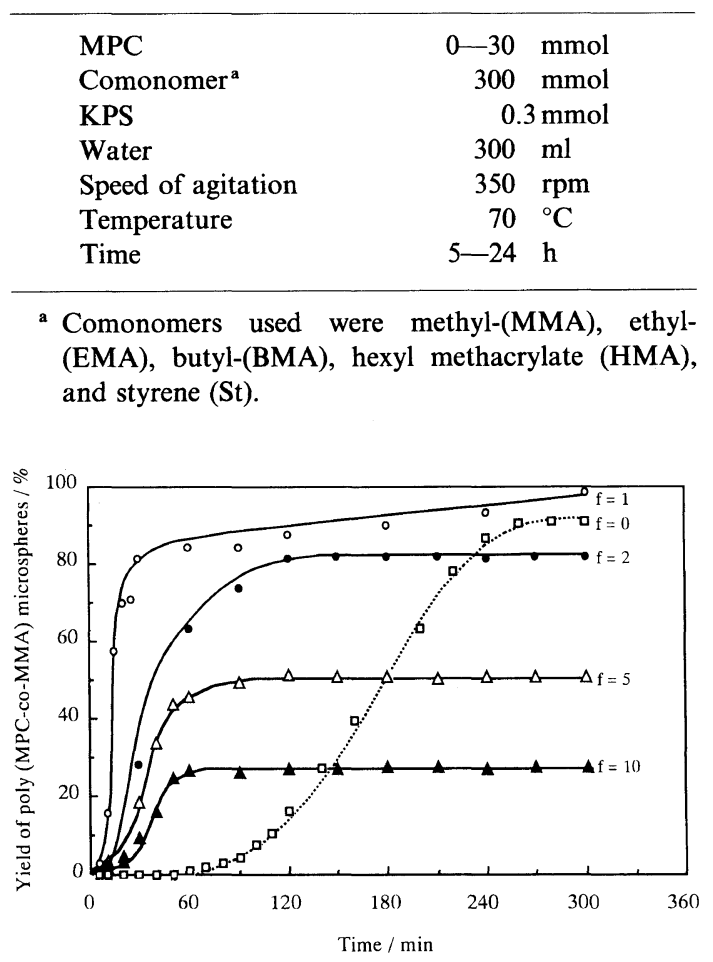

Figure 2. Polymer microspheres yield-time curves for the emulsion copolymerization of MPC and MMA at $70^{\circ} \mathrm{C}$. MMA, $300 \mathrm{mmol}$; KPS, $0.3 \mathrm{mmol}$; water, $300 \mathrm{ml} . f$ represents the mol\% of MPC to MMA monomer.

microspheres, poly(MPC-co-M), the emulsion copolymerization of MPC and MMA initiated by KPS as an initiator was carried out in the absence of emulsifier at $70^{\circ} \mathrm{C}$, varying the mol\% of MPC to MMA comonomer $(f)$ in feed from $f=1$ to $f=10$. The polymerization condition is given in Table I. For kinetics, polymerization was followed by sampling an aliquot of the emulsion from the stirred emulsion at prescribed time intervals. Poly(MPCco-MMA) microspheres-time curves for the copolymerization are plotted in Figure 2, together with those of poly(M) microspheres for the homopolymerization of MMA $(f=0)$. It was found that the addition of small amounts of MPC resulted in drastic increase in the rate of polymerization of MMA at an earlier stage.

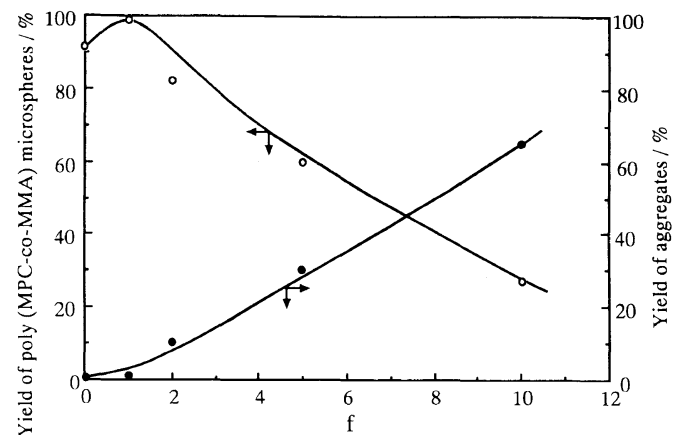

Figure 3. Effects of concentration of $\operatorname{MPC}(f)$ on yields of poly(MPC-co-MMA) microspheres and aggregates in the emulsion copolymerization of MPC and MMA at $70^{\circ} \mathrm{C}$. $f$ represents mol\% of MPC to MMA monomer.

This means that a larger number of particles was produced by increasing the solubility of MMA to water when MPC is present, and the Trommsdorff gel effect due to the increase in viscosity. These effects were described in the case of emulsifier-free emulsion copolymerization of St and sodium styrene sulfonate. ${ }^{21} \mathrm{~A}$ decrease in poly(MPC-co-MMA) microspheres yield and extensive increase in yield of coarse particles and its aggregates were also observed with increasing MPC concentration in the feed as shown in Figure 3. There are two possible reasons to explain the formation of aggregates: the aggregates probably originated from bridging flocculation in the presence of large amounts of MPC homopolymer, and by interacting the charged groups derived from KPS fragments with MPC moiety to reduce stability to the dispersion. Emulsifier-free emulsion copolymerization of MPC with various vinyl monomers was also carried out at $70^{\circ} \mathrm{C}$ with constant $\mathrm{mol} \%$ of MPC, $f=1$. The polymerization was continued under introducing nitrogen in the reaction vessel until the characteristic odor of comonomer was completely absent from mixture. Table II shows the results of characterization for a series of poly(MPC-co-M) microspheres. It was found that polymerization time to reach a final stage increases with decreasing hydrophilic nature of the comonomers. 
Table II. Characterization of poly(MPC-co-M) microspheres obtained from the emulsion copolymerization of MPC and various vinyl monomers

\begin{tabular}{|c|c|c|c|c|c|c|c|c|c|}
\hline \multirow{2}{*}{ Microspheres } & \multirow{2}{*}{$f^{a}$} & \multirow{2}{*}{$\frac{\text { Time }}{\mathrm{h}}$} & \multirow{2}{*}{$\frac{\text { Yield }}{\%}$} & Diameter $^{\mathbf{b}}$ & \multirow{2}{*}{$U^{\mathrm{c}}$} & \multicolumn{2}{|c|}{ In feed ${ }^{d}$} & \multicolumn{2}{|c|}{ XPS analysis $^{e}$} \\
\hline & & & & $\mathrm{nm}$ & & $10^{3} \mathrm{P} / \mathrm{C}$ & $10^{3} \mathrm{~N} / \mathrm{C}$ & $10^{3} \mathrm{P} / \mathrm{C}$ & $10^{3} \mathrm{~N} / \mathrm{C}$ \\
\hline Poly(MPC-co-MMA) & 1 & 5 & 98 & $160 \pm 34.0$ & 1.122 & 1.97 & 1.97 & 3.24 & 3.66 \\
\hline Poly(MPC-co-MMA) & 2 & 5 & 82 & $210 \pm 56.7$ & 1.348 & 3.83 & 3.83 & $(5.80)$ & $(5.16)$ \\
\hline Poly(MPC-co-MMA) & 5 & 5 & 60 & - & - & 9.01 & 9.01 & (9.11) & $(9.50)$ \\
\hline Poly(MPC-co-MMA) & 10 & 5 & 28 & - & - & 16.39 & 16.39 & $(11.33)$ & $(10.31)$ \\
\hline Poly(MPC-co-EMA) & 1 & 10 & 96 & $133 \pm 17.6$ & 1.055 & 1.64 & 1.64 & 2.09 & 2.16 \\
\hline Poly(MPC-co-BMA) & 1 & 10 & 90.6 & $123 \pm 18.7$ & 1.074 & 1.23 & 1.23 & $(4.10)$ & (4.37) \\
\hline Poly(MPC-co-HMA) & 1 & 12 & 87.8 & $84.4 \pm 26.7$ & 1.399 & 0.99 & 0.99 & $(2.73)$ & $(3.72)$ \\
\hline Poly(MPC-co-St) & 1 & 24 & 95 & $92.7 \pm 22.9$ & 1.210 & 1.23 & 1.23 & 3.88 & 4.11 \\
\hline
\end{tabular}

a $f$ represents mol\% of MPC to comonomer.

b Calculated from size distribution.

c $U=D_{\mathrm{w}} / D_{\mathrm{N}}$, where $D_{\mathrm{w}}$ and $D_{\mathrm{N}}$ are the weight-average and number-average diameters of microspheres, respectively.

d $\mathrm{P} / \mathrm{C}$ and $\mathrm{N} / \mathrm{C}$ are the ratios of atoms for $\mathrm{P}$ and $\mathrm{N}$ to $\mathrm{C}$ calculated in the feed. The composition in the bulk copolymer could not determine, because MPC content in the feed was too small to measure.

c $\mathrm{P} / \mathrm{C}$ and $\mathrm{N} / \mathrm{C}$ are the ratios of atoms for $\mathrm{P}$ and $\mathrm{N}$ to $\mathrm{C}$ obtained by XPS. Values in parenthesis are obtained from the fused particles samples.

\section{TEM Measurernts and Particle Size Distribu-} tion

Figure 4 shows TEM pictures of poly(MPCco-M) microspheres at $f=1$, together with those of corresponding poly $(\mathrm{M})$ microspheres. TEM pictures for the microspheres of poly(MPCco-MMA) at $f \geqq 2$, poly(MPC-co-BMA), and poly(MPC-co-HMA) could not be taken under the same conditions because the particles fuse with each other to form membranes in the course of drying. Particle size distribution of poly(MPC-co-M) microspheres was also measured as shown in Figure 5. The results are shown in Table II. It is apparent from the TEM pictures that particle sizes of poly(MPC-coEMA) microspheres and poly(MPC-co-St) microspheres are much smaller than those of poly(M) microspheres, while the copolymerization of MPC and MMA gives slightly larger size of particles than poly(MMA) microspheres. Increase in the diameter of poly(MPCco-M) microspheres except for the case of $\mathrm{St}$ comonomer was also noted with decreasing hydrophilic nature of $\mathbf{M}$ comonomers, whose hydrophilicity decreased in the order of MMA $>$ EMA $>$ BMA $>$ HMA $>$ St. The fact that the diameter of poly(MPC-co-St) microspheres is larger than that of poly(MPC-coHMA) microspheres is in conflict with the order of hydrophilicity of comonomers. It is well known that the solubility, polarity, and hydrophile-lipophile balance (HLB) of monomers, play important roles in emulsion polymerization. These differences in diameter of poly(MPC-co-M) microspheres and poly(M) microspheres are, therefore, accounted for by the difference in increase in solubility of comonomer when hydrophilic MPC is present. On comparing St and HMA comonomers, the addition of MPC may cause increase in solubility of the former much more than that of latter. It is concluded that particle diameter depends on the generation of charged stable oligomeric radicals which are converted to primary growing particles.

The uniformity ratio $(U)$ is defined by $U=D_{\mathrm{W}} / D_{\mathrm{N}}$, where $D_{\mathrm{W}}$ and $D_{\mathrm{N}}$ represent the weight-average and number-average diameter of polymer microspheres, respectively. Since in general polymer microspheres would be considered monodispersed when $U \leqq 1.01,{ }^{22,23}$ poly(MPC-co-EMA) microspheres and poly(- 
K. SugiYama and H. AoKI
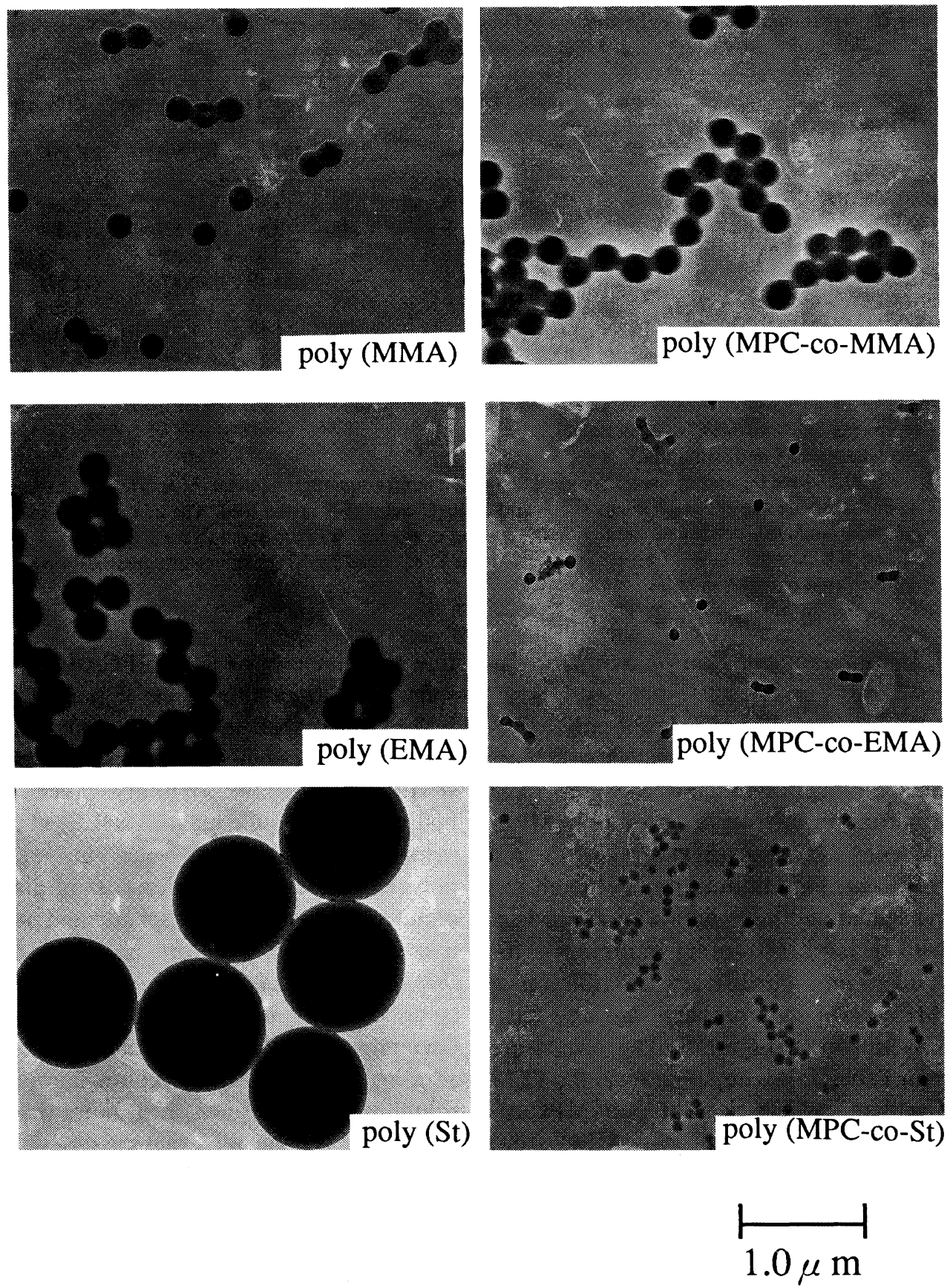

Figure 4. TEM micrographs of poly(MPC-co-M) microspheres at $f=1$ and homopolymer microspheres. $\times 20000$ 

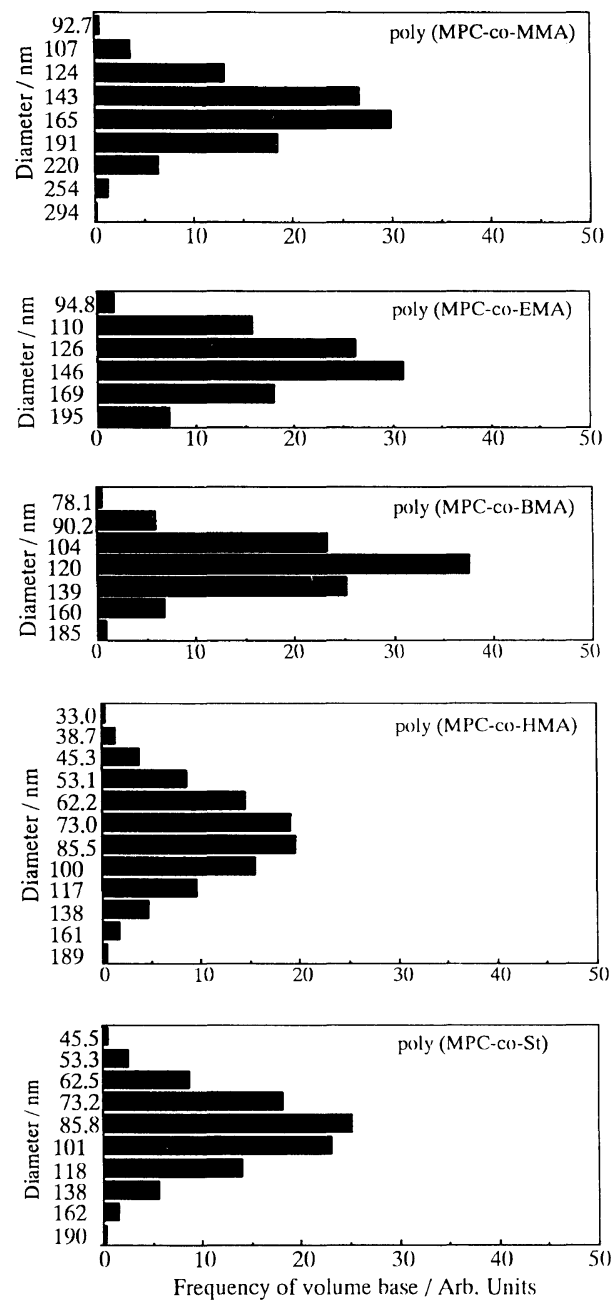

Figure 5. Particle size distribution for poly(MPC-co-M) microspheres at $f=1$.
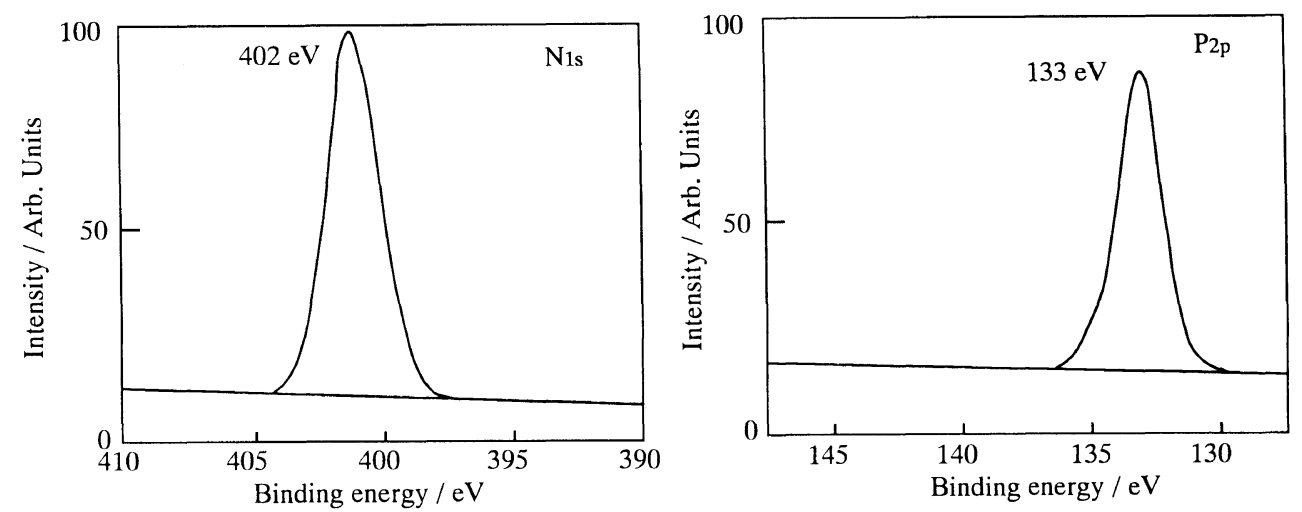

Figure 6. XPS for $\mathrm{N}_{1 \mathrm{~s}}$ and $\mathrm{P}_{2 \mathrm{p}}$ spectra of poly(MPC-co-MMA) microspheres at $f=1$. 


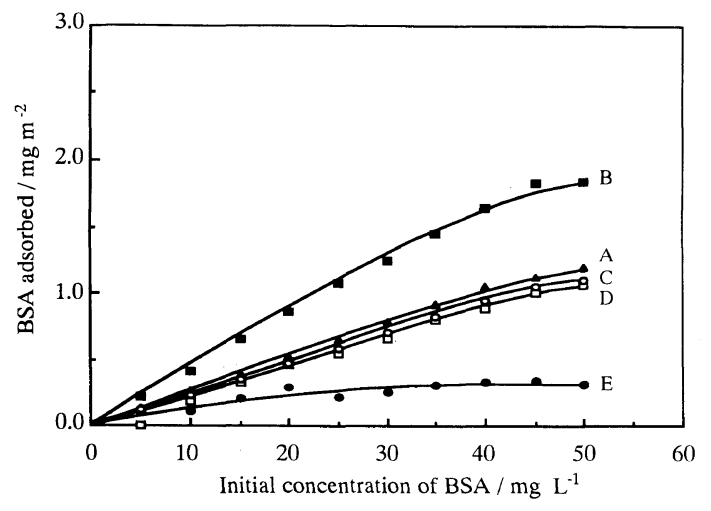

Figure 7. Adsorption of BSA onto various poly(MPCco-M) microspheres, pH 5.6, ionic strength 0.01 , at $25^{\circ} \mathrm{C}$ for $2 \mathrm{~h}$ : A, poly(MPC-co-St); B, poly(MPC-co-HMA); C, poly(MPC-co-BMA); D, poly(MPC-co-EMA); and E, poly(MPC-co-MMA).

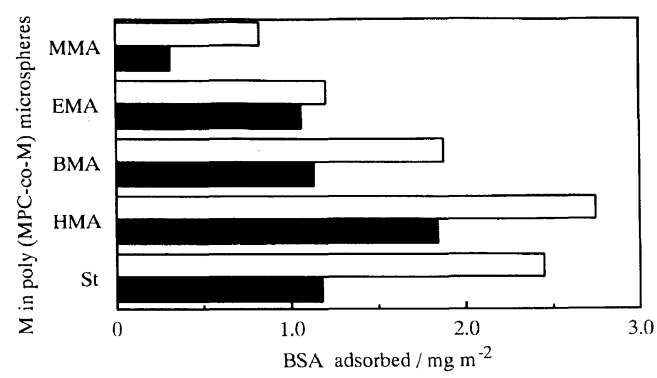

Figure 8. Comparison of adsorption of BSA onto poly(MPC-co-M) microspheres at $f=1$ and poly (M) microspheres, initial concentration of BSA $50 \mathrm{mgl}^{-1}, \mathrm{pH} 5.6$, ionic strength 0.01 , at $25^{\circ} \mathrm{C}$ for $2 \mathrm{~h}$. $\square$, poly(M) microspheres; $\square$, poly(MPC-co-M) microspheres.

It may be concluded that the MPC moiety is localized on the surface of particles.

\section{BSA Adsorption on Poly(MPC-co-M) Micro- spheres}

Interaction between poly(MPC-co-M) microspheres at $f=1$ and BSA was studied in order to obtain basic information for biomedical applications. The adsorption of BSA on poly(MPC-co-M) microspheres was examined in water at $\mathrm{pH} 5.6$, ionic strength 0.01 adjusted with $\mathrm{NaCl}$ aqueous solution, together with the adsorption experiments for poly(M) microspheres as control. This $\mathrm{pH}$ is close to the isoelectric point of BSA, at which molecules
Table III. Equilibrium water content for membranes obtained from polymer microspheres

\begin{tabular}{lcc}
\hline \multicolumn{1}{c}{ Membranes } & $f^{\mathrm{a}}$ & $\begin{array}{c}\text { Equilibrium water } \\
\text { content }^{\mathrm{b}} \times 100\end{array}$ \\
\hline Poly(MPC-co-MMA) & 1 & 1.31 \\
Poly(MPC-co-EMA) & 1 & 1.17 \\
Poly(MPC-co-BMA) & 1 & 0.93 \\
Poly(MPC-co-HMA) & 1 & 0.53 \\
Poly(MPC-co-St) & 1 & 0.57 \\
Poly(MMA) & 0 & 0.33 \\
Poly(EMA) & 0 & 0.29 \\
Poly(BMA) & 0 & 0.06 \\
Poly(HMA) & 0 & 0.05 \\
Poly(St) & 0 & 0.04 \\
\hline
\end{tabular}

${ }^{\text {a }} f$ represants mol\% of MPC to comonomer.

b At $25^{\circ} \mathrm{C}, \mathrm{pH} 7.40$.

form compact structures. ${ }^{24}$ Figure 7 shows the results of BSA adsorption on poly(MPC-co-M) microspheres. Figure 8 describes BSA adsorption on a series of microspheres of poly(MPCco-M) and poly(M) at $50 \mathrm{mgl}^{-1}$ of initial concentration of BSA. It can be said from Figure 8 that the introduction of phosphatidylcholine analogous moieties onto the surface of particles results in a decrease in BSA adsorption. Ishihara et al. reported that the membranes of poly(MPC-co-BMA), obtained by the solution copolymerization of MPC and BMA, absorb water well and become a hydrogel structure even MPC mole fraction in poly(MPC-co-BMA) is $0.04 .^{7}$ This membrane was found to reduce protein adsorption from human plasma ${ }^{4}$ and activation of platelets. ${ }^{5,6}$ Table III shows the equilibrium water content of a series of membranes prepared from polymer microspheres in $\mathrm{pH} 7.40$ at $25^{\circ} \mathrm{C}$. Comparing the membranes prepared from poly(MPC-co-M) microspheres at $f=1$ with corresponding poly(M) membranes, the former samples show larger equilibrium water content than the latter. The surface layer of the poly(MPC-co-M) microspheres is presumed to absorb water much more than membrane because the MPC moiety is concentrated on the surface of the particles. Taking into account 
the results reported by Ishihara, ${ }^{7}$ the surface of a series of poly(MPC-co-M) microspheres obtained here seems to form a partial hydrogel structure on the surface of the particles. In conclusion, reduction of adsorption of BSA on poly(MPC-co-M) microspheres is dependent on the hydrophilicity of $\mathrm{M}$ comonomer and MPC composition on the surface of particles.

Acknowledgments. The authors thank Mr. T. Ohashi of Western Industrial Research Institute of Hiroshima for measurement of XPS. Thanks are also due to Mr. T. Yoshida of Nippon Oil\& Fats Co., Ltd. Tsukuba Research Laboratory for the measurement of particle size distribution. The authors are grateful to the Environmental Science Institute of Kinki University for financial support. This study was also supported by a Grant-in-Aid for Science Research from Japan Private School Promotion Foundation.

\section{REFERENCES AND NOTES}

1. Z. Foltynowicz, K. Yamaguchi, B. Czajka, and S. L. Regen, Macromolecules, 18, 1394 (1985).

2. A. A. Durrani, J. A. Hayward, and D. Chapman, Biomaterials, 7, 121 (1986).

3. D. Letourneur, C. Douzon, and M. Jozefowicz, $J$. Polym. Sci., A, Polym. Chem. Ed., 29, 1367 (1991).

4. K. Ishihara, N. P. Ziats, B. P. Tierney, N. Nakabayashi, and J. M. Anderson, J. Biomed. Mater. Res., 25, 1397 (1991).

5. K. Ishihara, R. Aragaki, T. Ueda, A. Watanabe, and N. Nakabayashi, J. Biomed. Mater. Res., 24, 1069
(1990).

6. T. Ueda, K. Ishihara, and N. Nakabayashi, Kobunshi Ronbunshu, 48, 289 (1991).

7. K. Ishihara, T. Ueda, and N. Nakabayashi, Polym. J., 22, 355 (1990).

8. T. Ueda, K. Ishihara, and N. Nakabayashi, Makromol. Chem., Rapid Commun., 11, 345 (1990).

9. T. Ueda, H. Oshida, K. Kurita, K. Ishihara, and N. Nakabayashi, Polym. J., 24, 1259 (1992).

10. J. L. Robbins, G. A. Hill, B. N. Carle, J. H. Carlquist, and S. Marcus, Proceedings of the Society of Experiment Bio Medicine, Vol. 109, 1992, p 321.

11. A. Rembaum, S. P. S. Yen, and R. S. Molday, $J$. Macromol. Sci.-Chem., A13, 603 (1979).

12. H. Kawaguchi, N. Koiwai, and Y. Ohtsuka, J. Appl. Polym. Sci., 35, 743 (1988).

13. H. Sato, H. Morimoto, A. Nakajima, and $Y$. Noishiki, Polym. J., 16, 1 (1984).

14. K. Yamaguchi, S. Watanabe, and S. Nakahama, Makromol. Chem., 190, 1195 (1989).

15. K. Sugiyama, K. Shiraishi, K. Ohga, H. Shirahama, H. Tamai, H. Yasuda, and K. Kikukawa, Polym. J., 25, 521 (1993).

16. H. J. van den Hul and J. W. Vanderhoff, J. Colloid Interface Sci., 28, 336 (1968).

17. H. J. Lucas, F. W. Mitchell, and C. N. Scully, J. Am. Chem. Soc., 72, 5491 (1950).

18. R. E. Edmundson, Chem. Ind. (London), 1828 (1962).

19. T. Umeda, T. Nakaya, and M. Imoto, Makromol. Chem., Rapid Commun., 3, 457 (1982).

20. O. H. Lowry, N. J. Rosebrough, A. L. Farr, and R. J. Randall, J. Biol. Chem., 193, 265 (1951).

21. J. H. Kim, M. Chainey, M. S. El-Asser, and J. W. Vanderhoff, J. Polym. Sci., A, Polym. Chem., 30, 171 (1992).

22. H. Shirahama, H. Ohno, and T. Suzawa, Colloids and Surfaces, 60, 1 (1991).

23. A. Homola and R. O. James, J. Colloid Interface Sci., 59, 123 (1977).

24. T. Suzawa, H. Shirahama, and T. Fujimoto, J. Colloid Interface Sci., 86, 144 (1982). 